\title{
Hyperuricemia; the renewed interest in an old enemy
}

\author{
Bahar Bastani*(i) \\ School of Medicine, Saint Louis University, Saint Louis, Missouri 63110, USA
}

\section{ART I C L E I N F O}

Article Type:

Commentary

\section{Article History:}

Received: 8 May 2018

Accepted: 25 May 2018

Published online: 27 June 2019

\section{Implication for health policy/practice/research/medical education:}

Treatment with allopurinol may be effective in reversing some of the metabolic derangements of chronic kidney disease patients such as metabolic acidosis.

Please cite this paper as: Bastani B. Hyperuricemia; the renewed interest in an old enemy. J Renal Inj Prev. 2019;8(3):172-174. DOI: 10.15171/jrip.2019.32.
$\mathrm{H}$ yperuricemia (defined by serum uric acid levels above $7 \mathrm{mg} / \mathrm{dL}$ in men and 5.5 or $6 \mathrm{mg} /$ $\mathrm{dL}$ in women) is a common finding in patients with chronic kidney disease (CKD). From the early 1800 's hyperuricemia was recognized as a cause of gouty arthritis. At the same time hyperuricemia was suggested to have an underlying relationship with various cardiac and kidney diseases such as arteriolosclerosis, hypertension, cardiovascular and kidney diseases $(1,2)$. Some early epidemiological observations found that around $60 \%$ to $65 \%$ of patients with gout had arterial hypertension, $75 \%$ were obese, $20 \%-60 \%$ had mild to moderate degrees of CKD, 10\%-25\% developed end- stage kidney failure, $25 \%$ died with kidney failure, and 90\% developed cardiac disease (2-6). Moreover, it is now evident that $25 \%-50 \%$ of hypertensive patients have high serum uric acids, and up to $50 \%$ of asymptomatic hyperuricemias (serum uric acid $>6.5 \mathrm{mg} / \mathrm{dL}$ in females and $>7 \mathrm{mg} / \mathrm{dL}$ in men) have hypertension $(6,7)$. The histopathologic findings of "gouty nephropathy" consisted of glomerulosclerosis, renal arteriolosclerosis and interstitial fibrosis often containing focal urate crystal deposition in the interstitium was found in the autopsies of $79 \%-99 \%$ of patients with gout (8). However, since both hyperuricemia and cardiovascular diseases are commonly associated with risk factors such as old age, male gender, obesity, metabolic syndrome, type II diabetes, insulin resistance, hypertriglyceridemia, hypertension and CKD, hyperuricemia was considered a bystander and not a causative factor, except for gouty arthritis, and in the late 1980s uric acid was removed from routine chemistries. It took until late 1990s that high serum uric acid was recognized as a surrogate to renal disease and as a risk factor for developing hypertension, cardiovascular disease and metabolic syndrome (9-12). More recent epidemiologic studies, animal experiments, and human clinical studies have consistently shown that uric acid indeed has a causative role in development of hypertension, development of CKD, and heart diseases (2, $6,13-15)$. Some of the inconsistencies in the epidemiologic studies using multivariate analysis models to find an independent role for hyperuricemia in cardiovascular diseases, is partly due to a direct relationship between hyperuricemia and traditional cardiac risk factors such as hypertension, obesity, hyperlipidemia and male gender. However, hyperuricemia can be a causative risk factor for cardiac disorders without simultaneously being an independent risk factor. Moreover, in progressed CKD serum uric acid levels can increase because of the decreased GFR. Hyperuricemia itself might also contribute to the progression of renal disease as has been shown in animal studies $(13,15)$. A number of studies have now shown strong association between hyperuricemia and new onset of hypertension $(16,17)$, CKD and its progression (18-20), metabolic syndrome $(21,22)$, fatty liver $(23,24)$, cardiovascular diseases and the mortality associated with them $(11,12,25)$, and endothelial dysfunction $(26,27)$. Treatment with allopurinol, a xanthine oxidase inhibitor, has been shown to slow the development of CKD $(28,29)$, decrease blood pressure in the new onset juvenile hypertension (30), improve endothelial function (31-33), and decrease cardiovascular morbidity and mortality (29,34-38). The effect of allopurinol on improving metabolic acidosis was firstly reported by Bayram et al (39). In 30 patients with CKD stages 2-4, they found 
that administration of $300 \mathrm{mg} / \mathrm{d}$ of allopurinol for three months resulted in significant improvement in endothelial function as measured by flow-mediated dilation over the forearm, a significant improvement in creatinine clearance and serum bicarbonate levels, compared to a controlled group (39). The randomized controlled clinical trial by Gholami et al, presented in this issue of the journal is of interest. It shows that patients with CKD stages 2-4 and serum uric acid levels between 6-10 mg/ $\mathrm{dL}$ with documented metabolic acidosis, who received allopurinol 100mg daily, versus placebo control group who received vitamin $\mathrm{B} 1$, have a significant rise in serum bicarbonate level and GFR (40). This report adds further evidence to our current knowledge that hyperuricemia is not just an innocent bystander in the CKD patients, and it contributes to its progression and also to some of the metabolic derangements associated with CKD such as metabolic acidosis. Moreover, it shows that treatment with allopurinol may be effective in reversing some of these metabolic derangements such as metabolic acidosis.

Author's contribution

$\mathrm{BB}$ is the single author of the paper.

\section{Conflicts of interest}

The author declare no conflict of interest.

\section{Ethical considerations}

Ethical issues (including plagiarism, data fabrication, double publication) have been completely observed by the author.

\section{Funding/Support}

None.

\section{References}

1. Davies N Jr. The cardiovascular and renal relations and manifestations of gout. J Am Med Assoc. 1897;29:261-2. doi: 10.1001/jama.1897.02440320005001a.

2. Nakagawa T, Kang DH, Feig D, Sanchez-Lozada LG, Srinivas TR, Sautin Y, et al. Unearthing uric acid: an ancient factor with recently found significance in renal and cardiovascular disease. Kidney Int. 2006;69:1722-5.

3. Berger L, Yu TF. Renal function in gout. IV. An analysis of 524 gouty subjects including long-term follow-up studies. Am J Med. 1975;59:605-13.

4. Talbott JH, Terplan KL. The kidney in gout. Medicine (Baltimore). 1960;39:405-67.

5. Wallace SL. Gout and hypertension. Arthritis Rheum. 1975; 18:721-4

6. Mazzali M, Kanbay M, Segal MS, Shafiu M, Jalal D, Feig DI, et al. Uric acid and hypertension: cause or effect? Curr Rheumatol Rep. 2010;12:108-17.

7. Klein R, Klein BE, Cornoni JC, Maready J, Cassel JC, Tyroler HA. Serum uric acid. Its relationship to coronary heart disease risk factors and cardiovascular disease, Evans County, Georgia. Arch Intern Med. 1973;132:401-10.
8. Gonick HC, Rubini ME, Gleason IO, Sommers SC. The Renal Lesion in Gout. Ann Intern Med. 1965;62:667-74.

9. Johnson RJ, Kivlighn SD, Kim YG, Suga S, Fogo AB. Reappraisal of the pathogenesis and consequences of hyperuricemia in hypertension, cardiovascular disease, and renal disease. Am J Kidney Dis. 1999;33:225-34.

10. Feig DI, Kang DH, Johnson RJ. Uric acid and cardiovascular risk. N Engl J Med. 2008;359:1811-21.

11. Borghi C. The role of uric acid in the development of cardiovascular disease. Curr Med Res Opin. 2015;31 Suppl 2:1-2.

12. Borghi C, Rosei EA, Bardin T, Dawson J, Dominiczak A, Kielstein JT, et al. Serum uric acid and the risk of cardiovascular and renal disease. J Hypertens. 2015;33(9):1729-41. doi: 10.1097/HJH.0000000000000701.

13. Nakagawa T, Mazzali M, Kang DH, Sanchez-Lozada LG, Herrera-Acosta J, Johnson RJ. Uric acid-a uremic toxin? Blood Purif. 2006;24:67-70.

14. Mazzali M, Hughes J, Kim YG, Jefferson JA, Kang DH, Gordon KL, et al. Elevated uric acid increases blood pressure in the rat by a novel crystal-independent mechanism. Hypertension. 2001;38(5):1101-6.

15. Kang DH, Nakagawa T, Feng L, Watanabe S, Han L, Mazzali $\mathrm{M}$, et al. A role for uric acid in the progression of renal disease. J Am Soc Nephrol. 2002;13:2888-97.

16. Kuwabara M, Hisatome I, Niwa K, Hara S, Roncal-Jimenez CA, Bjornstad $\mathrm{P}$, et al. Uric acid is a strong risk marker for developing hypertension from prehypertension: a 5-year japanese cohort study. Hypertension. 2018;71:78-86.

17. Kuwabara M, Niwa K, Hisatome I, Nakagawa T, RoncalJimenez CA, Andres-Hernando A, et al. Asymptomatic Hyperuricemia Without Comorbidities Predicts Cardiometabolic Diseases: Five-Year Japanese Cohort Study. Hypertension. 2017;69:1036-44. doi: 10.1161/ HYPERTENSIONAHA.116.08998.

18. Filiopoulos V, Hadjiyannakos D, Vlassopoulos D. New insights into uric acid effects on the progression and prognosis of chronic kidney disease. Ren Fail. 2012;34:51020. doi: 10.3109/0886022X.2011.653753.

19. Kang DH, Chen W. Uric acid and chronic kidney disease: new understanding of an old problem. Semin Nephrol. 2011;31:447-52.

20. Johnson RJ, Nakagawa T, Jalal D, Sanchez-Lozada LG, Kang DH, Ritz E. Uric acid and chronic kidney disease: which is chasing which? Nephrol Dial Transplant. 2013;28(9):22218. doi: $10.1093 / \mathrm{ndt} / \mathrm{gft} 029$.

21. Yadav D, Lee ES, Kim HM, Lee EY, Choi E, Chung CH. Hyperuricemia as a Potential Determinant of Metabolic Syndrome. J Lifestyle Med. 2013;3:98-106.

22. Kanbay M, Jensen T, Solak Y, Le M, Roncal-Jimenez C, Rivard C, et al. Uric acid in metabolic syndrome: From an innocent bystander to a central player. Eur J Intern Med. 2016;29:3-8.

23. Jensen T, Niwa K, Hisatome I, Kanbay M, Andres-Hernando A, Roncal-Jimenez CA, et al. Increased Serum uric acid over five years is a risk factor for developing fatty liver. Sci Rep. 2018;8:11735. doi: 10.1038/s41598-018-30267-2.

24. Lanaspa MA, Sanchez-Lozada LG, Choi YJ, Cicerchi C, Kanbay M, Roncal-Jimenez CA, et al. Uric acid induces hepatic steatosis by generation of mitochondrial 
oxidative stress: potential role in fructose-dependent and -independent fatty liver. J Biol Chem. 2012;287:40732-44.

25. Borghi C, Rodriguez-Artalejo F, De Backer G, Dallongeville J, Medina J, Nuevo J, et al. Serum uric acid levels are associated with cardiovascular risk score: A post hoc analysis of the EURIKA study. Int J Cardiol. 2018;253:16773. doi: 10.1016/j.ijcard.2017.10.045.

26. Choi YJ, Yoon Y, Lee KY, Hien TT, Kang KW, Kim KC, et al. Uric acid induces endothelial dysfunction by vascular insulin resistance associated with the impairment of nitric oxide synthesis. FASEB J. 2014;28:3197-204. doi: 10.1096/ fj.13-247148.

27. Kanellis J, Kang DH. Uric acid as a mediator of endothelial dysfunction, inflammation, and vascular disease. Semin Nephrol. 2005;25(1):39-42.

28. Siu YP, Leung KT, Tong MK, Kwan TH. Use of allopurinol in slowing the progression of renal disease through its ability to lower serum uric acid level. Am J Kidney Dis. 2006;47:51-9.

29. Goicoechea M, Garcia de Vinuesa S, Verdalles U, Verde E, Macias N, Santos A, et al. Allopurinol and progression of CKD and cardiovascular events: long-term follow-up of a randomized clinical trial. Am J Kidney Dis. 2015;65:543-9.

30. Feig DI, Soletsky B, Johnson RJ. Effect of allopurinol on blood pressure of adolescents with newly diagnosed essential hypertension: a randomized trial. JAMA. 2008;300:924-32.

31. Cicero AFG, Pirro M, Watts GF, Mikhailidis DP, Banach M, Sahebkar A. Effects of Allopurinol on Endothelial Function: A Systematic Review and Meta-Analysis of Randomized Placebo-Controlled Trials. Drugs. 2018;78:99-109. doi: 10.1007/s40265-017-0839-5

32. Kanbay M, Huddam B, Azak A, Solak Y, Kadioglu GK, Kirbas I, et al. A randomized study of allopurinol on endothelial function and estimated glomular filtration rate in asymptomatic hyperuricemic subjects with normal renal function. Clin J Am Soc Nephrol. 2011;6:1887-94.

33. Kanbay M, Siriopol D, Nistor I, Elcioglu OC, Telci O, Takir $\mathrm{M}$, et al. Effects of allopurinol on endothelial dysfunction: a meta-analysis. Am J Nephrol. 2014;39:348-56. doi: 10.1159/000360609

34. Borghi C, Desideri G. Urate-lowering drugs and prevention of cardiovascular disease: the emerging role of xanthine oxidase inhibition. Hypertension. 2016;67:496-8.

35. Chen JH, Lan JL, Cheng CF, Liang WM, Lin HY, Tsay GJ, et al. Effect of urate-lowering therapy on all-cause and cardiovascular mortality in hyperuricemic patients without gout: a case-matched cohort study. PLoS One. 2015;10:e145193. doi: 10.1371/journal.pone.0145193.

36. MacIsaac RL, Salatzki J, Higgins P, Walters MR, Padmanabhan S, Dominiczak AF, et al. Allopurinol and cardiovascular outcomes in adults with hypertension. Hypertension. 2016;67:535-40. doi: 10.1161/ HYPERTENSIONAHA.115.06344.

37. Pontremoli R. The role of urate-lowering treatment on cardiovascular and renal disease: evidence from CARES, FAST, ALL-HEART, and FEATHER studies. Curr Med Res Opin. 2017;33:27-32.

38. Wei L, Mackenzie IS, Chen Y, Struthers AD, MacDonald TM. Impact of allopurinol use on urate concentration and cardiovascular outcome. Br J Clin Pharmacol. 2011;71:6007.

39. Bayram D, Tugrul Sezer M, Inal S, Altuntas A, Kidir V, Orhan $\mathrm{H}$. The effects of allopurinol on metabolic acidosis and endothelial functions in chronic kidney disease patients. Clin Exp Nephrol. 2015;19:443-9. doi: 10.1007/ s10157-014-1012-z.

40. Gholami D, Hami H, Hasanzamani B, Miri M. Impact of allopurinol on metabolic acidosis in patients with chronic kidney disease; a randomized controlled-trial. Renal Inj Prev. 2019;8:216-220. doi: 10.15171/jrip.2019.40.

Copyright (C) 2019 The Author(s); Published by Nickan Research Institute. This is an open-access article distributed under the terms of the Creative Commons Attribution License (http://creativecommons.org/licenses/by/4.0), which permits unrestricted use, distribution, and reproduction in any medium, provided the original work is properly cited. 